\title{
High domestic pig contribution to the local gene pool of free-living European wild boar: a case study in Poland
}

\author{
Artur Dzialuk $^{1}$ (D) $\cdot$ Ewa Zastempowska $^{2} \cdot$ Radosław Skórzewski $^{2}$ • \\ Magdalena Twarużek ${ }^{2} \cdot$ Jan Grajewski $^{2}$
}

Received: 7 January 2017 / Accepted: 30 July 2017 /Published online: 12 August 2017

(C) The Author(s) 2017. This article is an open access publication

\begin{abstract}
Rates of hybridization between wild and domesticated animals appear to be increasing worldwide. Recent results suggest that genetic introgression from domestic swine into European wild boar is much more common in local populations than expected, based on pan-European studies. Thus, we screened the genetic purity of 265 free-living wild boars from two hunting areas in Poland by genotyping the melanocortin receptor 1 gene $(M C 1 R)$ for polymorphism. Unexpectedly, high numbers of individuals with domestic genes (24\%) were identified. This suggests that mixed ancestry may be common in Polish wild boar. Among admixed individuals, backcrosses with domestic pig and/or introgressed wild boars were detected (2\%). Multiple commercial domestic pig breeds are possibly involved in the introgression observed in the study populations. In addition, the absence of significant differences in the frequency of wildtype allele among two hunting areas suggests high dispersal of individuals and gene flow among populations. We conclude that further study is needed to better understand the mechanisms and sources of introgression in wild boars in Poland.
\end{abstract}

Communicated by: Joanna Stojak

Artur Dzialuk

dzialuk@ukw.edu.pl

1 Faculty of Natural Sciences, Institute of Experimental Biology, Department of Genetics, Kazimierz Wielki University, Al. Powstańców Wielkopolskich 10, 85-090 Bydgoszcz, Poland

2 Faculty of Natural Sciences, Institute of Experimental Biology, Department of Physiology and Toxicology, Kazimierz Wielki University, Chodkiewicza 30, 85-064 Bydgoszcz, Poland
Keywords Wild boar - Domestic swine - Sus scrofa . Introgression $\cdot M C 1 R$

\section{Introduction}

Hybridization is the phenomenon of gene pool mixing between different taxa. If hybrid offspring survive, are fertile, and contribute their alleles to future generations by backcrossing, the process is called introgressive hybridization (introgression). Introgression is one of the primary threats to global biodiversity (Rhymer and Simberloff 1996; Allendorf et al. 2001). For example, evidence is accumulating that rates of hybridization between wild species and their domestic relatives are increasing (Randi 2008; Canu et al. 2014). This hybridization may occur intentionally or accidentally (Fulgione et al. 2016). Domestic genes may provide a fitness advantage for individuals of some species (Anderson et al. 2009; Goedbloed et al. 2013a; Fulgione et al. 2016). However, there is growing concern that introgression from domestic into wild animals may compromise the genetic integrity of the latter (Largiadèr 2008). The resulting loss of genetic diversity may correspond to a reduction in fitness and adaptive potential, as well as favor disease transmission (Allendorf et al. 2001; Todesco et al. 2016).

Wild boar (WB; Sus scrofa) is an important game species that is highly managed throughout its range in Eurasia and Northwest Africa. This species is the ancestor of domestic swine (DS; Sus scrofa domestica), and WB can successfully crossbreed with DS. This can unintentionally occur where there is open-air domestic swine farming, which is a common management system in Bulgaria, Croatia, Iberia, Corsica, and Sardinia (Scandura et al. 2008; Apollonio et al. 2010). Intentional hybridization between WB and DS also commonly occurs for the purpose of producing less aggressive animals, 
obtaining larger litter sizes, increasing piglet growth rates, achieving hybrid vigor, creating "wild boar-like" hybrids to be released for hunting, or fraudulent WB meat substitution (Booth 1995; Aravena and Skewes 2007; Randi 2008; Fontanesi et al. 2014).

Wild boar population sizes have been increasing worldwide, and WB is considered an agricultural and forestry pest in many countries (Dzięciołowski and Clarke 1989; Gipson et al. 1998; Waithman et al. 1999; Apollonio et al. 2010; García et al. 2011; Wilson 2013). Wild boar is currently one of the world's most widespread large mammals and is the second most abundant ungulate in Europe (Herrero et al. 2008; Apollonio et al. 2010; Massei et al. 2015). More than three million WB are harvested annually in Europe (Massei et al. 2015). The trend of increasing WB populations is also evident in Poland, where the harvest of WB has increased from 118,000 in 2000 to 264,000 in 2015 (Central Statistical Office of Poland 2015).

The spread of WB may be due to several factors (Massei and Genov 2004; Vetter et al. 2015). One recent hypothesis is that introgressive hybridization between WB and DS increases WB fitness and invasiveness (García et al. 2011; Frantz et al. 2013; Goedbloed et al. 2013a). However, the degree to which WB and DS hybridization occurs is currently uncertain. One viewpoint is that intensive farming during the last two centuries has progressively reduced the risk of hybridization (Scandura et al. 2011a). This is supported by data suggesting that there are marginal DS gene contributions to the genetic make-up of free-living WB in Europe (5-10\% in Scandura et al. 2008, 2011a and 11\% in Canu et al. 2016). However, more extensive introgression has recently been reported in WB populations located in Luxembourg (27\%) and the Emilia-Romagna region in Italy (17.1\%) (Frantz et al. 2013; Fontanesi et al. 2014). Recent preliminary research using genome-wide single-nucleotide polymorphism (SNP) data documents variable levels of introgression in Europe and suggests the possible existence of a hybrid zone(s) in Europe (Iacolina et al. 2016a).

In Poland, the risk of unintentional hybridization between WB and DS is considered minimal because DS management is primarily intensive and indoors, thereby reducing the opportunities for direct contact between domestic and wild animals. Moreover, intentional hybridization is prohibited by Polish law except on registered farms. Thus, high levels of recent introgression are not expected. However, because research to date is based on only 44 individuals, data on introgression into WB in Poland is inconclusive. While Babicz et al. (2013) found three individuals with domestic alleles among 10 WBs from Lublin (eastern Poland), Canu et al. (2016) found only one introgressed individual among seven Polish WBs. Neither Gongora et al. $(2003)(n=15)$ nor Fang et al. (2009) $(n=12)$ found evidence of hybridization among Polish WBs.
Sequence diversity at the melanocortin receptor $1(M C 1 R)$ locus is widely used to distinguish between meat originating from WB, DS, and their hybrids, as well as to detect introgression from DS into WB (Giuffra et al. 2000; Koutsogiannouli et al. 2010; Frantz et al. 2013; Fontanesi et al. 2014; Canu et al. 2016). In addition, mtDNA sequencing, microsatellite genotyping, and a single-nucleotide polymorphism (SNP) assay have been used to look for evidence of introgression (Giuffra et al. 2000; Scandura et al. 2008, 2011b, Frantz et al. 2012, 2013, 2015, Goedbloed et al. 2013b, a; HerreroMedrano et al. 2013; Iacolina et al. 2016b).

Unfortunately, the resources of most wildlife geneticists are inadequate for using these markers. Thus, we used a simple diagnostic test for $M C 1 R$ gene polymorphism to screen for the presence of domestic alleles in a large number of Polish WBs sampled in two hunting areas. We also genotyped DS breeds used for commercial crossbreeding in Poland and used these genotypes as reference material for study of WB genetic purity. Specifically, we seek to answer the following questions: (1) has contact with DS resulted in introgression of domestic genes into free-living WB populations and (2) is there a significant difference in the frequency of wild-type alleles between hunting areas in Poland?

\section{Methods}

\section{Blood sample collection}

A total of 359 blood samples were genotyped. Ten samples from each of eight DS breeds $(n=80)$ were obtained from either the National Research Institute of Animal Production (Kraków-Balice, Poland) or breeders who participate in "The National Breeding Program" and "The Programme of Genetic Resource Protection". These samples included both commercial breeds (Pietrain, Hampshire, Duroc) and Polish native pig breeds (Polish White Landrace, Polish Large White, Złotnicka White, Złotnicka Spotted and Puławska). Three WB $\times$ DS (Duroc) hybrids housed at the Institute of Applied Biotechnology and Basic Sciences, University of Rzeszów, and eleven DS hybrids (Polish Large White $\times$ Duroc) were also used in this study. In addition, blood samples were taken from 265 free-living animals identified in the field as WBs. All animals were legally hunted in accordance with the national WB regulations during the 2011-2015 hunting seasons. Sample collection was performed by licensed hunters as a part of routine wildlife management and hunting club shooting programs without bias towards age, sex, or coat color. Animals were shot in two neighboring hunting areas in north-central Poland: Krajna $(n=93)$ and Kujawy $(n=172)$. These natural populations are relatively well isolated from each other by landscape barriers, including rivers (Noteć, Warta, and Wisła) and a road network (Fig. 1). 


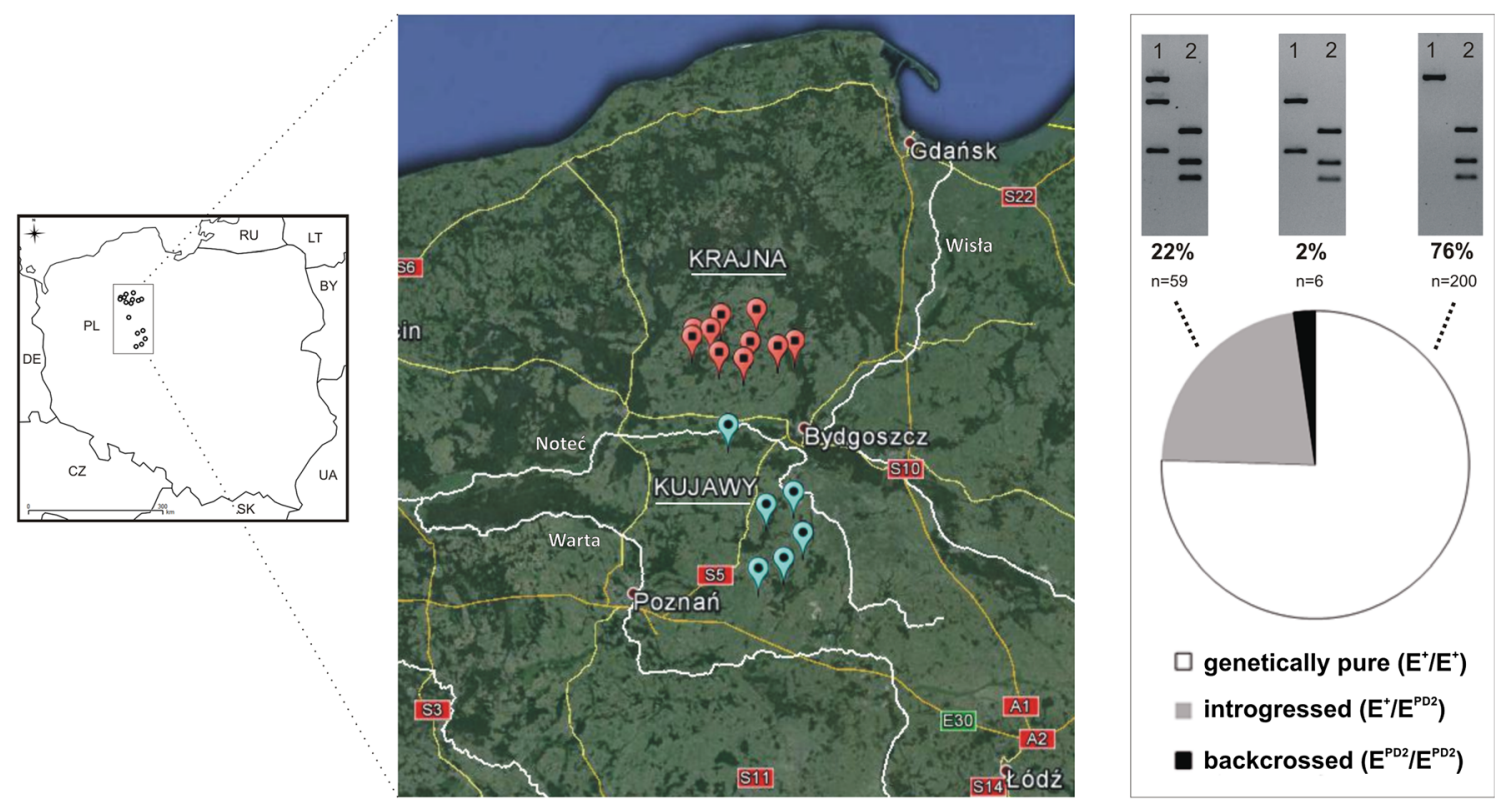

Fig. 1 Distribution of sampling sites and polymorphism of wild boar in Poland. Numbers represent digestion patterns of $M C 1 R$ gene with BspHI and BstUI (1 and 2, respectively)

\section{Analysis of the MC1R gene}

Two loci, Extention $(E)$ and Agouti $(A)$, control much of variation in coat color and pattern in mammals (Barsh 1996). The melanocortin receptor 1 (MC1R) encoded by Extention locus is a G-protein coupled receptor determining the switch between production of black/brown eumelanin and red/yellow pheomelanin. A series of alleles of the $M C 1 R$ gene have been found so far in pigs. The wild-type $\left(E^{+}\right)$allele has been identified in WBs, the Hungarian Mangalica DS breed and DS raised in free or semi-free conditions in Sardinia (Canu et al. 2016). Meanwhile, in other DS breeds, because of different human needs or cultural preferences, domestication and human selective pressures caused coat color variation generated by non-synonymous mutations (Fang et al. 2009; Li et al. 2010). The phenotypically defined alleles in porcine $M C 1 R$ gene are black $\left(E^{D 1}\right.$ and $\left.E^{D 2}\right)$, black spotting $\left(E^{P}\right)$, and red $(e)$. Moreover, several additional allelic variants are also reported based on subsequent sequence analyses (Andersson 2003; Fang et al. 2009). The black alleles $\left(E^{D 1}\right.$ and $\left.E^{D 2}\right)$ are dominant over $E^{P}$ and $e$, whereas $E^{P}$ is incompletely dominant over $e$ (Aravena and Skewes 2007; Dun et al. 2007). MC1R genotypes and corresponding coat color phenotypes are presented in Table 1.

We adopted methodology based on PCR-RFLP analysis of the MC1R gene (Fajardo et al. 2008). We used nomenclature for porcine $M C 1 R$ alleles described by Fang, with modifications proposed by Fontanesi et al. (Fang et al. 2009; Fontanesi et al. 2014). Since alleles $E^{P}$ and $E^{D 2}$ cannot be separated from each other, they were combined as one allele $E^{P D 2}$. Briefly, we were able to differentiate between six genotypes in WB, DS, and their hybrids: $E^{P D 2} / E^{P D 2} ; e / e ; E^{P D 2} / e ; E^{+} / E^{+} ; E^{+} / E^{P D 2}$; $E^{+} / e$ (for details see Fig. 2).

Amplification of the MC1R gene was performed using the Phusion Blood Direct PCR Kit (Thermo Scientific, Affibody $\mathrm{AB}$, Sweden) according to manufacturer's directions, with minor modifications. Briefly, PCRs were carried out directly from whole blood placed onto Whatman FTA Classic Cards (Whatman, UK) that were pretreated by washing in Purification Reagent (Whatman, UK) and TE Buffer (Whatman, UK). PCRs were performed in a total volume of $30 \mu \mathrm{l}$ containing $1 \times$ Phusion Blood PCR Buffer, $1 \mu \mathrm{M}$ each $M C 1 R$ primer, $0.6 \mu$ of Phusion Blood II DNA Polymerase, and a 2.0-mm diameter circle of FTA Classic Card.

The primers MC1R-FW and MC1R-REV failed to amplify under our PCR conditions (Fajardo et al. 2008). Consequently, we redesigned both primers based on the DNA sequences of the MC1R gene of S. scrofa deposited in GenBank (accession numbers, EU443645 and DQ191184). Finally, we analyzed the variation at the MC1R using forward primer: 5'-AGTG

Table 1 Genotypes and phenotypes at the MC1R locus in wild boar and domestic swine

\begin{tabular}{llll}
\hline $\begin{array}{l}\text { Extension } \\
\text { genotype }\end{array}$ & Coat color phenotype & Origin & $\begin{array}{l}\text { Breed } \\
\text { examples }\end{array}$ \\
\hline$E^{+} / E^{+}$ & Wild type (reddish/brown) & European/Asian & $\mathrm{WB}$ \\
$E^{D 1} / E^{D 1}$ & Uniform black & Asian & Meishan \\
$E^{D 2} / E^{D 2}$ & Uniform black & European & Hampshire \\
$E^{P} / E^{P}$ & $\begin{array}{c}\text { Black spotting on a red or } \\
\text { white background }\end{array}$ & European & Pietrain \\
$e / e$ & Uniform red & European & Duroc \\
\hline
\end{tabular}




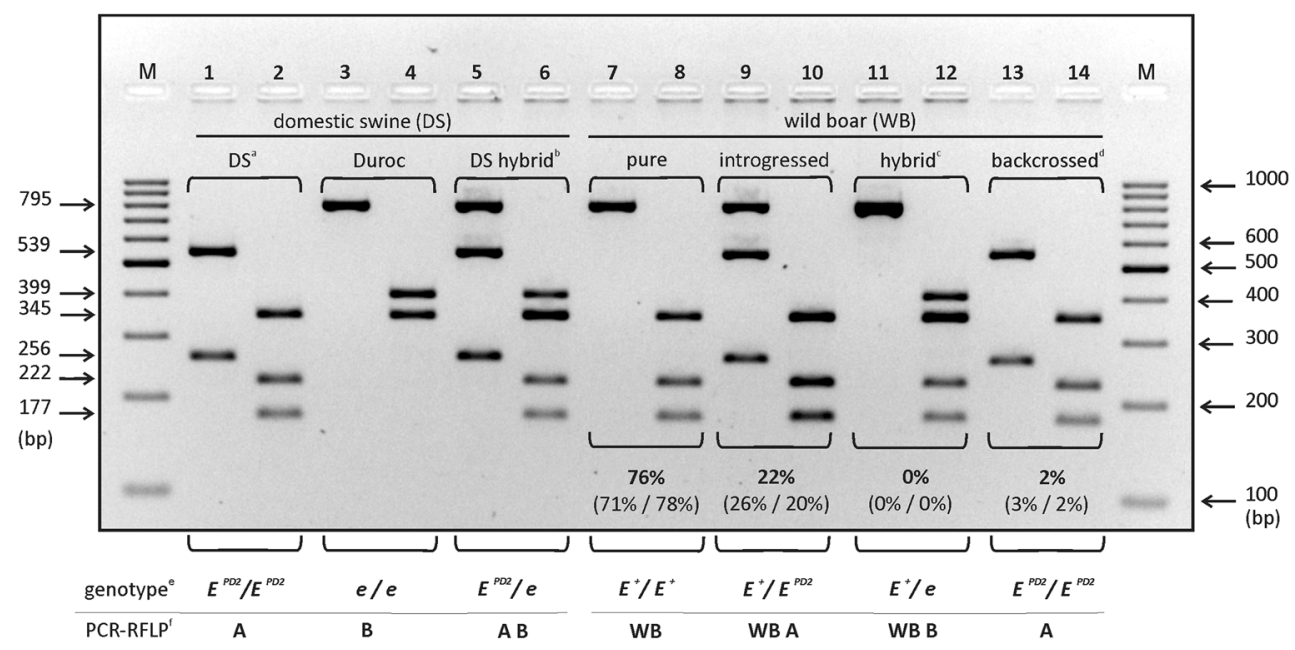

Fig. 2 PCR-RFLP analysis of $M C 1 R$ gene in domestic swine and wild boar using BspHI (lines 1, 3, 5, 7, 9, 11, 13) and BstUI (lines 2, 4, 6, 8, 10, 12,14 ) and corresponding genetic profiles (below the picture). Lengths of restriction fragments are shown on the left. Frequencies of $M C 1 R$ genotypes are given for total population and two hunting regions in Poland-Krajna and Kujawy, respectively (in parentheses). $M$ molecular weight marker (size of DNA fragments on right); ${ }^{a}$ genetic

profile common to domestic swine breeds: Pietrain, Hampshire, Polish White Landrace, Polish Large White, Złotnicka White, Złotnicka Spotted, Puławska, ${ }^{b}$ Polish Large White $\times$ Duroc; ${ }^{c} \mathrm{WB} \times$ Duroc, ${ }^{d}$ backcrosses with domestic swine and/or introgressed individuals, ${ }^{e}$ alleles described by Fang et al. (2009) with modification proposed by Fontanesi et al. (2014), ${ }^{f}$ PCR-RFLP profiles according to Fajardo et al. (2008)

CCTGGAGGTGTCCATTCCC-3', and reverse primer: 5'CGTAGATGAGGGGGTCCĀCGATGGA-3' (modifications underlined).

Negative and positive PCR controls were included in each set of reactions (water and Duroc, respectively). Amplification was run in a C1000 Touch Thermal Cycler (Bio-Rad, USA) using a two-step thermal profile without an annealing step, as recommended for the Phusion Blood Direct PCR Kit. PrePCR denaturation occurred at $98{ }^{\circ} \mathrm{C}$ for $5 \mathrm{~min}$. This was followed by 35 cycles of denaturing at $98^{\circ} \mathrm{C}$ for $1 \mathrm{~s}$, extension at $72{ }^{\circ} \mathrm{C}$ for $15 \mathrm{~s}$, and a final extension step at $72{ }^{\circ} \mathrm{C}$ for $1 \mathrm{~min}$. The PCR products were checked by electrophoresis on $1 \%$ agarose gels containing $0.5 \mu \mathrm{g} / \mathrm{ml}$ ethidium bromide in $1 \times$ TBE buffer. Ten microliters of each PCR products was digested with $10 \mathrm{U}$ of BspHI or BstUI restriction endonuclease and $1 \times$ CutSmart Buffer (New England Biolabs, UK) in a total volume of $20 \mu \mathrm{l}$ for $1 \mathrm{~h}$. Digested DNA fragments were separated on $2 \%$ high resolution agarose $(\mathrm{Nu}$ Micropor, Prona, EU) in $1 \times \mathrm{TBE}$ buffer at $5 \mathrm{~V} / \mathrm{cm}$. DNA fragments were visualized with the Gel Doc XR+ System (Bio-Rad, USA). Generuler $^{\mathrm{TM}} 100$ bp DNA Ladder (Thermo Scientific, USA) was used as a DNA molecular weight marker.

Significance of difference in the frequency of the wild-type allele between two hunting areas was tested using the chisquare test.

\section{Results}

We were able to amplify 795 bp $M C 1 R$ fragments in all samples. Restriction analyses with BspHI and BstUI

endonucleases provided DNA fragments in expected sizes (Fig. 2). Duroc breed pigs had genotype e/e. All Polish native DS breeds and two commercial breeds (Pietrain and Hampshire) carried the common genotype $\left(E^{P D 2} / E^{P D 2}\right)$ (Table 2).

Most WBs carried only the wild-type $E^{+}$allele $(76 \%$ in the total sample; 71 and $78 \%$ in Krajna and Kujawy, respectively). However, $24 \%$ of WB showed signs of DS contribution $\left(E^{+}\right.$ $E^{P D 2}$ and $E^{P D 2} / E^{P D 2}$ ) (Fig. 1). Differences in the frequency of WBs carrying the domestic allele $E^{P D 2}$ among the two hunting areas (29 and 22\% in Krajna and Kujawy, respectively) were not statistically significant.

Table 2 Individual genotypes identified at the $M C 1 R$ locus in domestic swine and wild boar populations in Poland

\begin{tabular}{|c|c|c|c|c|c|}
\hline \multirow[t]{2}{*}{ Origin } & \multirow[t]{2}{*}{ No. of animals } & \multicolumn{4}{|c|}{ Genotypes (no. of animals) } \\
\hline & & $E^{+} / E^{+}$ & $E^{+} / E^{P D 2}$ & $E^{P D 2} / E^{P D 2}$ & ele \\
\hline \multicolumn{6}{|c|}{ Domestic swine } \\
\hline DS & & - & - & 70 & - \\
\hline Duroc & & - & - & - & 10 \\
\hline \multicolumn{6}{|l|}{ Wild boar } \\
\hline Krajna & 93 & 66 & 24 & 3 & - \\
\hline Kujawy & 172 & 134 & 35 & 3 & - \\
\hline Total & 265 & 200 & 59 & 6 & - \\
\hline
\end{tabular}

$D S$ domestic swine breeds $(n=10$ each): Pietrain, Hampshire, Polish White Landrace, Polish Large White, Złotnicka White, Złotnicka Spotted, Puławska 


\section{Discussion}

Our newly developed primers and direct PCR method (without DNA extraction) were easy to employ and have wide applicability. We used $M C 1 R$ polymorphism to show that WBs from two hunting areas are not genetically purebred. We also showed that the Duroc DS breed had genotype e/e, while all Polish native DS breeds and two commercial breeds (Pietrain and Hampshire) carried the common genotype $\left(E^{P D 2} / E^{P D 2}\right)$. The same results for Złotnicka White, Złotnicka Spotted, and Puławska were observed in Poland by Babicz et al. (2013). However, this is the first report on genetic variation in $M C 1 R$ gene in two local pig breeds: Polish White Landrace and Polish Large White.

Mixed ancestry has been found worldwide in WB populations. The Polish WB populations we studied have some of Europe's highest levels of DS introgression. These levels are similar to those found in regions where DS are reared in semifree conditions (up to 10-20\% in Canu et al. 2016) or WB populations that have been restocked with captive-bred individuals that have been cross-bred with DS (27\% in Frantz et al. 2013). Since analysis using $M C 1 R$ alleles is likely to severely underestimate the number of WB with a domestic ancestor (Frantz et al. 2012, 2013), we cannot exclude the possibility that the real rate of introgression may be much higher than observed in this study. However, our result should be interpreted with caution and confirmed by DNA markers that would reveal the admixture level (e.g., SNPs or microsatellites).

Our results contradict Scandura et al. (2011a) and Goedbloed et al. (2013a) suggesting that the contribution of DS genes to the WB gene pool in Europe is marginal. In fact, introgression of domestic genes may reach much higher levels at very local scale (Fulgione et al. 2016), especially in regions where open-air pig farming (Canu et al. 2016) and/or hybridization in captivity (Gongora et al. 2003; Canu et al. 2014) and/or restocking with farmed WB that had been cross-bred with DS (Frantz et al. 2012, 2013; McDevitt et al. 2013), are practiced.

Crosses between WB and DS were relatively common during domestication processes but also noted throughout Europe at present (White 2011). Nowadays, illegal and unauthorized hybridization in captivity and subsequent accidental escapes or intentional releases of captive-bred individuals constitutes the major source of the spread of domestic genes into wild boar populations (Koutsogiannouli et al. 2010; Apollonio et al. 2010; Frantz et al. 2012, 2013; McDevitt et al. 2013; Canu et al. 2014; Murakami et al. 2014). We believe that high DS contribution to the local gene pool of free-living WB in Krajna and Kujawy may result from the clandestine release and/or escape of farmed WBs, that had been crossed with DS in captivity. Moreover, the potential sources of hybridization in the study area may include five registered WB $\times$ DS hybrid farms located within a radius of $60 \mathrm{~km}$ surrounding the study sites.

It should be noted that the intentional hybridization is prohibited by Polish law since 2008 and breeding of hybrids is allowed only in 37 farms registered by the General Directorate for Environmental Protection. Similarly, breeding of the WB is allowed exclusively in 34 farms registered by the Polish Ministry of the Environment. Unfortunately, the numbers of farmed WBs and hybrids are unknown and the registration of WB farms does not guarantee that WBs are genetically pure. Thus, it seems that genetic controls in Polish WB farms should be enforced to identify and selectively remove admixed individuals. Moreover, it seems that the threat to the native gene pools and genetic integrity of WB in Poland is represented by both legal and illegal WB $\times$ DS hybrids farms. Although, to date, no massive escape or release of farmed individuals was recorded in Poland, we cannot confidently exclude the possibility that escapes or illegal releases from farms were performed in the study area. Alternatively, hybrid origin could result from historic crosses between WB and DS in semi-wild condition, followed by genetic drift (Frantz et al. 2013). Until the modern era, the seasonal practice of releasing DS in the forest provided plenty of opportunities of crossbreeding with WB (White 2011; Marshall et al. 2014). Although, recessive or semi-dominant $M C 1 R$ alleles may be masked by dominant genes, the coat color is a remarkable trait which is likely to undergo strong selective pressure in the wild. Thus, the introgressed alleles driving color variation are likely to be purged within a limited number of generations. A recent study by Battocchio et al. (2017) seems to support the hypothesis that phenotypically anomalous WBs are not fully fit for life in the wild and poorly accepted by their cohort. Hence, the presented results suggest ongoing or very recent hybridization rather than historic processes. However, these hypotheses need further insights.

A lack of significant difference in the frequency of wild-type allele among two WB populations in Poland may be due to opportunities for gene flow that arise during occasional migration of individuals to neighboring populations. Since WB can migrate over distances of up to 150-500 km (Andrzejewski and Jezierski 1978; Jerina et al. 2014), the isolation by roads and waterways may be not fully effective between Krajna and Kujawy.

The sources of Polish WB population introgression are unclear, but multiple DS breeds may be involved. Our results clearly indicate that only the DS allele $E^{P D 2}$ was introgressed into WB populations in the study area. This is not surprising because the vast majority of DS breeds in Poland are fixed for this allele (Fig. 2). However, the absence of introgressed WB individuals carrying the domestic allele $e\left(E^{+} / e\right)$ suggests that the Duroc breed did not contribute to the introgression. Although, lack of genetic introgression from Duroc into WB has also been suggested in the Netherlands, Luxembourg, and Germany based on SNP analysis (Goedbloed et al. 2013a), four hybrids ( $E+/ e$ ) were reported in Italy (Fontanesi et al. 2014). The reasons why allele $e$ has been not introgressed into WB in Poland may be that the Duroc breed has been brought to Poland recently. Since the DS breeding system in Poland is based on crossing Polish White Landrace 
or Polish Large White dams with Pietrain, Duroc, or Hampshire sires, the participation of Duroc breed in commercial crossing is rather low (4\%). Unfortunately, since the allele $E^{P D 2}$ was detected in all DS breeds except Duroc (Fig. 2), the methods used in this study cannot be used to detect the origin of introgression in greater detail.

While the origins of introgression are uncertain, there are several possibilities for why individuals with the WB phenotype would carry the DS genotype $\left(E^{P D 2} / E^{P D 2}\right)$ found in this study (2-3\%, Fig. 1). One potential explanation is that there have been backcrosses between DS $\left(E^{P D 2} / E^{P D 2}\right)$ and introgressed WBs $\left(E^{+} / E^{P D 2}\right)$. Another possibility is that there have been crosses between introgressed WBs $\left(E^{+} / E^{P D 2}\right)$. A third scenario would be crosses between backcrossed WBs $\left(E^{P D 2} / E^{P D 2}\right)$. A low number of second generation or later hybrids and past introgression were observed in other European populations using the $M C 1 R$ locus or a genome-wide singlenucleotide polymorphism (Koutsogiannouli et al. 2010; Goedbloed et al. 2013a; Fontanesi et al. 2014). However, we cannot confidently exclude the possibility that the allele $E^{P D 2}$ occurs naturally at very low frequency in other populations of free-living WBs in Poland.

Polish WB populations are reduced by approximately $80 \%$ annually, due to high harvest rates. This may unintentionally promote the spread of "domestic genes" by reducing the size of local populations to the extent that DS alleles have a greater chance of being fixed. This is most likely to occur at the local scale where there is open-air pig farming, hybridization in captivity, or restocking of farms with WB cross-bred with DS (Gongora et al. 2003; Frantz et al. 2012, 2013; McDevitt et al. 2013; Canu et al. 2014; Fulgione et al. 2016). Disruption of WB population structure could also favor migration of individuals with DS alleles. This would be consistent with the lack of significant difference in the frequency of wild-type allele among two Polish WB populations we studied. Migration and local-scale concerns raise uncertainty as to the appropriate sampling scale for identifying introgression of DS genes into WB populations. Further investigation is needed to better understand the genetic make-up of contemporary Polish WB populations, as well as the mechanisms and sources of DS allele contributions.

Acknowledgments This research did not receive any specific grant from funding agencies in the public, commercial, or not-for-profit sectors. We would like to thank two anonymous referees for their comments that helped improve the manuscript significantly.

\section{Compliance with Ethical Standards}

Conflict of Interest The authors declare that they have no conflict of interest.

Ethical approval All applicable international, national, and institutional guidelines for the care and use of animals were followed.
Open Access This article is distributed under the terms of the Creative Commons Attribution 4.0 International License (http:// creativecommons.org/licenses/by/4.0/), which permits unrestricted use, distribution, and reproduction in any medium, provided you give appropriate credit to the original author(s) and the source, provide a link to the Creative Commons license, and indicate if changes were made.

\section{References}

Allendorf FW, Leary RF, Spruell P, Wenburg JK (2001) The problems with hybrids: setting conservation guidelines. Trends Ecol Evol 16: 613-622. doi:10.1016/S0169-5347(01)02290-X

Anderson TM, vonHoldt BM, Candille SI et al (2009) Molecular and evolutionary history of melanism in North American gray wolves. Science 323:1339-1343. doi:10.1126/science.1165448

Andersson L (2003) Melanocortin receptor variants with phenotypic effects in horse, pig, and chicken. Ann N Y Acad Sci 994:313-318

Andrzejewski R, Jezierski W (1978) Management of a wild boar population and its effects on commercial land. Acta Theriol (Warsz) 23: 309-339. doi:10.4098/AT.arch.78-23

Apollonio M, Andersen R, Putman R (2010) European ungulates and their management in the 21st century. Cambridge University Press

Aravena P, Skewes O (2007) European wild boar purebred and Sus scrofa intercrosses. Discrimination proposals. A review. Agro Cienc 23: $133-147$

Babicz M, Pastwa M, Skrzypczak E, Buczyński JT (2013) Variability in the melanocortin 1 receptor (MC1R) gene in wild boars and local pig breeds in Poland. Anim Genet 44:357-358. doi:10.1111/age. 12023

Barsh GS (1996) The genetics of pigmentation: from fancy genes to complex traits. Trends Genet 12:299-305. doi:10.1016/01689525(96)10031-7

Battocchio D, Iacolina L, Canu A, Mori E (2017) How much does it cost to look like a pig in a wild boar group? Behav Process 138:123-126. doi:10.1016/j.beproc.2017.03.001

Booth W (1995) Wild boar farming in the United Kingdom. IBEX J Mt Ecol 3:245-248

Canu A, Costa S, Iacolina L et al (2014) Are captive wild boar more introgressed than free-ranging wild boar? Two case studies in Italy. Eur J Wildl Res 60:459-467. doi:10.1007/s10344-014-0804-5

Canu A, Vilaça ST, Iacolina L et al (2016) Lack of polymorphism at the MC1R wild-type allele and evidence of domestic allele introgression across European wild boar populations. Mamm Biol - Z Für Säugetierkd 81:477-479. doi:10.1016/j.mambio.2016.01.003

Central Statistical Office of Poland (2015) Forestry 2015. Data of the Agricultural Property Agency, Directorate General of the State Forests and the Polish Hunting Association Available at: http://stat. gov.pl/en/topics/agriculture-forestry/forestry/forestry-2015,1,6.html (last accessed September 30, 2016)

Dun G, Li X, Cao H et al (2007) Variations of melanocortin receptor 1 (MC1R) gene in three pig breeds. J Genet Genomics Yi Chuan Xue Bao 34:777-782. doi:10.1016/S1673-8527(07)60088-5

Dzięciołowski RM, Clarke CMH (1989) Age structure and sex ratio in a population of harvested feral pigs in New Zealand. Acta Theriol (Warsz) 34:525-536

Fajardo V, González I, Martín I et al (2008) Differentiation of European wild boar (Sus scrofa scrofa) and domestic swine (Sus scrofa domestica) meats by PCR analysis targeting the mitochondrial Dloop and the nuclear melanocortin receptor 1 (MC1R) genes. Meat Sci 78:314-322. doi:10.1016/j.meatsci.2007.06.018 
Fang M, Larson G, Soares Ribeiro H et al (2009) Contrasting mode of evolution at a coat color locus in wild and domestic pigs. PLoS Genet 5:e1000341. doi:10.1371/journal.pgen.1000341

Fontanesi L, Ribani A, Scotti E et al (2014) Differentiation of meat from European wild boars and domestic pigs using polymorphisms in the MC1R and NR6A1 genes. Meat Sci 98:781-784. doi:10.1016/j. meatsci.2014.07.026

Frantz AC, Massei G, Burke T (2012) Genetic evidence for past hybridisation between domestic pigs and English wild boars. Conserv Genet 13:1355-1364. doi:10.1007/s10592-012-0379-1

Frantz AC, Zachos FE, Kirschning J et al (2013) Genetic evidence for introgression between domestic pigs and wild boars (Sus scrofa) in Belgium and Luxembourg: a comparative approach with multiple marker systems. Biol J Linn Soc 110:104-115. doi:10.1111/bij. 12111

Frantz LAF, Schraiber JG, Madsen O et al (2015) Evidence of long-term gene flow and selection during domestication from analyses of Eurasian wild and domestic pig genomes. Nat Genet 47:1141-1148

Fulgione D, Rippa D, Buglione M et al (2016) Unexpected but welcome. Artificially selected traits may increase fitness in wild boar. Evol Appl 9:769-776. doi:10.1111/eva.12383

García G, Vergara J, Lombardi R (2011) Genetic characterization and phylogeography of the wild boar Sus scrofa introduced into Uruguay. Genet Mol Biol 34:329-337. doi:10.1590/S141547572011005000015

Gipson PS Kansas SU, Hlavachick B, Berger T (1998) Range expansion by wild hogs across the central United States

Giuffra E, Kijas JM, Amarger V et al (2000) The origin of the domestic pig: independent domestication and subsequent introgression. Genetics 154:1785-1791

Goedbloed DJ, Megens HJ, Van Hooft P et al (2013a) Genome-wide single nucleotide polymorphism analysis reveals recent genetic introgression from domestic pigs into Northwest European wild boar populations. Mol Ecol 22:856-866. doi:10.1111/j.1365-294X.2012. 05670.x

Goedbloed DJ, van Hooft P, Megens H-J et al (2013b) Reintroductions and genetic introgression from domestic pigs have shaped the genetic population structure of Northwest European wild boar. BMC Genet 14:43. doi:10.1186/1471-2156-14-43

Gongora J, Peltoniemi OAT, Tammen I et al (2003) Analyses of possible domestic pig contribution in two populations of Finnish farmed wild boar. Acta Agric Scand Sect Anim Sci 53:161-165. doi:10.1080/ 09064710310010602

Herrero J, García-Serrano A, García-González R (2008) Reproductive and demographic parameters in two Iberian wild boar Sus scrofa. Acta Theriol (Warsz) 53:355-364. doi:10.1007/BF03195196

Herrero-Medrano JM, Megens H-J, Groenen MA et al (2013) Conservation genomic analysis of domestic and wild pig populations from the Iberian Peninsula. BMC Genet 14:1-13. doi:10.1186/ 1471-2156-14-106

Iacolina L, Bakan J, Cubric-Curik V, et al (2016a) Hybridization among wild boars, local breeds and commercial breeds - preliminary results. Proceedings of Conference on Conservation Genomics "Congenomics 2016", Campus de Vairão, Portugal, 3-6 May 2016 (pp. 61)

Iacolina L, Scandura M, Goedbloed DJ et al (2016b) Genomic diversity and differentiation of a managed island wild boar population. Heredity 116:60-67. doi:10.1038/hdy.2015.70

Jerina K, Pokorny B, Stergar M (2014) First evidence of long-distance dispersal of adult female wild boar (Sus scrofa) with piglets. Eur J Wildl Res 60:367-370. doi:10.1007/s10344-014-0796-1
Koutsogiannouli EA, Moutou KA, Sarafidou T et al (2010) Detection of hybrids between wild boars (Sus scrofa scrofa) and domestic pigs (Sus scrofa f. domestica) in Greece, using the PCR-RFLP method on melanocortin-1 receptor (MC1R) mutations. Mamm Biol - Z Für Säugetierkd 75:69-73. doi:10.1016/j.mambio.2008.08.001

Largiadèr CR (2008) Hybridization and introgression between native and alien species. In: Nentwig DW (ed) Biological invasions. Springer, Berlin Heidelberg, pp 275-292

Li J, Yang H, Li J et al (2010) Artificial selection of the melanocortin receptor 1 gene in Chinese domestic pigs during domestication. Heredity 105:274-281. doi:10.1038/hdy.2009.191

Marshall FB, Dobney K, Denham T, Capriles JM (2014) Evaluating the roles of directed breeding and gene flow in animal domestication. Proc Natl Acad Sci 111:6153-6158. doi:10.1073/pnas.1312984110

Massei G, Genov PV (2004) The environmental impact of wild boar. Galemys 16:135-145

Massei G, Kindberg J, Licoppe A et al (2015) Wild boar populations up, numbers of hunters down? A review of trends and implications for Europe. Pest Manag Sci 71:492-500. doi:10.1002/ps.3965

McDevitt AD, Carden RF, Coscia I, Frantz AC (2013) Are wild boars roaming Ireland once more? Eur J Wildl Res 59:761-764. doi:10. 1007/s10344-013-0721-z

Murakami K, Yoshikawa S, Konishi S et al (2014) Evaluation of genetic introgression from domesticated pigs into the Ryukyu wild boar population on Iriomote Island in Japan. Anim Genet 45:517-523. doi:10.1111/age.12157

Randi E (2008) Detecting hybridization between wild species and their domesticated relatives. Mol Ecol 17:285-293. doi:10.1111/j.1365294X.2007.03417.x

Rhymer JM, Simberloff D (1996) Extinction by hybridization and introgression. Annu Rev Ecol Syst 27:83

Scandura M, Iacolina L, Apollonio M (2011a) Genetic diversity in the European wild boar Sus scrofa: phylogeography, population structure and wild $\mathrm{x}$ domestic hybridization. Mammal Rev 41:125-137. doi:10.1111/j.1365-2907.2010.00182.x

Scandura M, Iacolina L, Cossu A, Apollonio M (2011b) Effects of human perturbation on the genetic make-up of an island population: the case of the Sardinian wild boar. Heredity 106:1012-1020. doi:10. 1038/hdy.2010.155

Scandura M, Iacolina L, Crestanello B et al (2008) Ancient vs. recent processes as factors shaping the genetic variation of the European wild boar: are the effects of the last glaciation still detectable? Mol Ecol 17:1745-1762. doi:10.1111/j.1365294X.2008.03703.X

Todesco M, Pascual MA, Owens GL et al (2016) Hybridization and extinction. Evol Appl 9:892-908. doi:10.1111/eva.12367

Vetter SG, Ruf T, Bieber C, Arnold W (2015) What is a mild winter? Regional differences in within-species responses to climate change. PLoS One 10:e0132178. doi:10.1371/journal.pone.0132178

Waithman JD, Sweitzer RA, Van Vuren D et al (1999) Range expansion, population sizes, and management of wild pigs in California. J Wildl Manag 63:298-308. doi:10.2307/3802513

White S (2011) From globalized pig breeds to capitalist pigs: a study in animal cultures and evolutionary history. Environ Hist 16:94-120. doi:10.1093/envhis/emq143

Wilson CJ (2013) The establishment and distribution of feral wild boar (Sus scrofa) in England. Wildl Biol Pract. doi:10.2461/ wbp.2014.un.1 